\title{
Informal Democracy in Patras, Greece: A Mechanism for Improved Planning?
}

\begin{abstract}
Greek spatial planning reality faces the problems like sprawl and illegal settlements outside the building zones, underpinned by the conventional self-financed real estate development model under the patronage of the national government. In case of transportation congestion problems, the formal planning proved to be even more ineffective and unpopular. Therefore, non-institutionalized supplement to formal planning is considered highly effective: informal planning relies upon the principles of collaborative dialogue, networks and trustful relationships among the relevant players. The article describes the informal planning procedure - the test planning method - analyzed against the theoretical background of communicative rationality, on the one hand, and critically assessed through the practical implementation in the case of Peloponnesian city of Patras on the other. As a result, the article highlights the successful phases of the test planning, nevertheless pointing to its shortcomings, which could be expected in the societies with a dominant political cronyism.
\end{abstract}

\section{Highlights:}

- $\quad$ Effective coordination makes the core of informal planning procedures.

- $\quad$ Communicative rationality principles coincide with a nature of informal planning.

- Informal planning affects a long-term process of the planning culture change.

Keywords: informal planning; communicative rationality; test planning method; Greece 


\section{Introduction: Spatial Challenges in Greece}

In recent years, global socio-economic transformations have strongly challenged the spatial planning practice. The countries of Eastern and Southern Europe in particular have experienced a prolonged economic crisis with tremendous impact on numerous facilities, services, and infrastructures. Increasing demand for housing, the provision of low-interest mortgages, and the significant, but not sustainable investments in major urban projects manifest the crisis unevenly across space (Papaioannou \& Nikolakopoulou 2016). The relatively inexpensive mortgage credit encouraged households to purchase homes built on greenfield sites across Greece, while regional and local governments neglected planning policies promoting sustainable compact land development (Giannakourou 2011; Getimis \& Giannakourou 2014). In fact, the authorities overlooked the costs of sprawl feeding political patronage, thus spreading risk to overextended homeowners living on the urban edge (Zifou 2015). In late 2009 international financial markets collapsed stranding millions of new owners with speculative debt few could sustain. The results were catastrophic for southern economies generating a prolonged recession. Massive state-financed rescue and recapitalization of the financial system staved off complete collapse. Modest national government fiscal stimuli attempted to stimulate economic growth and reduce unemployment (Hadjimichalis 2011). The shock wave crippled Greece: not only it had too much private debt ended up in speculative private real estate investment, but national (and regional/local) governments had borrowed to fund infrastructure that encouraged such inefficient development - for instance, building roads for unsustainable sprawling development rather than trains for compact sustainable development (Zifou 2015). Regional and local spatial problems in Greece result from practices largely indifferent to spatial planning, but sensitive to the private plans of lenders and developers with ties to local political elites (Knieling \& Othengrafen 2016; Romero, Jiménez \& Viloria 2012).

Current spatial problems flow from the complexity of interactions among hierarchical levels of political and economic competition among private firms (developers, lenders, investors, land owners), households (owners, renters), political organizations (political parties, advocacy groups, non-profits) and public officials (elected, administrators, professionals). All these agents make plans, but the ensuing decisions are neither transparent nor coordinated. Ironically, state administrative bodies and public organizations responsible for strategic spatial planning miss opportunities for democratic cooperation that might reduce unnecessary conflicts and delays for important infrastructure projects (Papamichail 2015; Pappas, Kalamiotis \& Karidi 2013). Free for all privatization encourages inefficient outsourcing and speculation as private plans pay lip service to environmental sustainability and public 
accountability (Reimer, Getimis \& Blotevogel 2014; Getimis \& Giannakourou 2014). The HRADF (Hellenic Republic Asset Development Fund) created with effusive liberal rhetoric encouraged speculative peripheral development and then changed the laws to make low quality unsustainable projects legitimate. Public sector planners responsible for assuring the quality of future spatial development have not done much to resist these efforts. Worse, some invite corrupt practices to approve substandard development (Giannakourou 2011).

The liberal privatization efforts were supposed to replace the tradition of centralized bureaucratic planning that did little to support the efficacy of practical democracy for spatial planning in Greece. But the reformers used the rhetoric of democratic reform to undermine the requirements for a truly democratic spatial planning. The nation that invented democracy must take steps to revive and practice it. This starts with including citizens in collaborative initiatives where public and private interests intersect as plans for places (Knieling \& Othengrafen 2009). The decentralization of spatial planning responsibilities to regional and local authorities in the 1990s proposed procedural mechanisms for citizen involvement in spatial planning (Giannakourou 2011). But these did not take hold because local professionals remained tied to an urbanism tradition that focused on regulating physical form rather than making spatial plans (Newman \& Thornley 1996). The bureaucratic administrative culture dominates practice encouraging reliance on narrow disciplinary expertise unable and unwilling to cope with the increasingly complex spatial problems that pose recurring crises for regions and localities (Pappas 2017).

Take for instance the problem of transportation congestion and recent large-scale projects to remedy the problem including the Hellinikon (the former main airport of Athens) redevelopment (Milionis 2010; Komninos 2014), the construction of the new metro line in Thessaloniki (Roukouni et al. 2016), or the proposed railway development in Patras (Papamichail 2015). Each took years to plan with little collaboration and in each case the proposed solution proved both unpopular and ineffective. The reasons behind such a situation is in public plans that followed formal conventions. Formal planning retains the top-down approach focused on privileged political interests, thus often unrelated to the complex causes and interests shaping the regional spatial problem. This affects the attention of local government planners who also remain attached to disciplinary conventions that treat plans as physical blueprints rather than strategic guides for multiple agents. On top of these, the effects of privatization embrace the speculation and corruption. In sum, formal planning proved unable to integrate and resolve conflict among competing interests. Therefore, informal practices that focus on setting and solving spatial problems collaboratively may offer practical remedies for complex spatial problems (Scholl 2017; Pappas 2017). 
Briefly put, informal planning activities sacrifice authority for responsibility. Instead of focusing on what you can control you focus on those whose actions shape the future consequences for a spatial planning situation (e.g., the flooding, the traffic, etc.), as well as those who will bear most of these consequences. Current formal conventions usually keep the people in these respective social positions and locations apart. Informal action brings some of these people together to collaborate making plans for the place. The formal planning process gets squeezed between the contest of political elections and the competition of economic investment. The informal approach invites politicians and investors to join in temporary collaboration without the strictures of formal roles. The collaboration is democratic and focused on deliberation among these participants. The payoff is not increased power, but improved judgment about what to do as each learn from one another to conceive and compare problems and solutions for a place that combines causal assessment and political judgment (Briassoulis 1997; Scholl 2017).

In general, the attribute of informality of the planning process has been gaining its importance with the evolution of deliberative democracy as a context within which the process is embedded. This has both theoretical and practical implications. From the theoretical perspective, the informal planning revolves around the 'collaborative-argumentative turn' in planning (Innes 1995; Healey 1997; Forester 1999). In practice, informal planning has been largely discussed and implemented (to various extent) in both the developed and developing societies (Scholl 2017; Scholl, Staub \& Vinzens 2013; Buchner et al. 2004; Keresztély \& Scott 2012; Foldi 2006; Vojvodiková 2010). This paper documents how the informal process was used to conduct spatial planning for a transportation problem in Greece. How well did informal planning work within the formal Greek system tied to the adversarial interests contesting for project influence in representative democracy?

The article first describes the spatial infrastructure problem for Patras, the third largest Greek city. Next comes the analysis of informal planning as a complement to the formal system and its cognitive and practical contributions. The central section explains the theoretical ideas animating the informal approach and how the test planning method put these principles to practical use organizing plan making for Patras. The concluding sections interpret the effectiveness of the informal approach arguing that informality works best for complex problems that formal systems cannot handle well. 


\section{The Patras Case: Spatial and Infrastructural Discrepancies}

Once the main trading and cultural hub in the 19th and early 20th centuries, Patras lacks interregional railway connections with Athens. Formal system plans promote Patras as a national strategic corridor of PATHE (Patras-Athens-Thessaloniki-Eidomeni) that will bridge the East-West division of high-performance transport infrastructures. However, current plans for large-scale infrastructural projects include decisions by private actors like large private Chinese firms investing in port improvements for Piraeus and Thessaloniki. Formal planning system efforts plagued by administrative disagreements and political contests has produced competing unilateral project plans undermining hopes for coordination and failing to make the necessary adjustments to yield practical railway integration feasible and affordable. Protecting administrative turf and political authority excludes crucial actors while encouraging unrealistic options stuck in opposition to each other.

The main formal system actors - the OSE (Hellenic Railways Organization) and the ERGOSE 1 (the OSE subsidiary company in charge of real estate) - compete for authority. A rigid bureaucratic structure encourages top-down decision-making. This works fine for simple problems, but not for complex system problems that require an adaptive response combining a plurality of viewpoints, ideas and solutions including the interests and needs of relevant actors with a stake in the future. One set of formal actors promotes the plan for a tunnel - an expensive solution that fits the interests of a few powerful firms; even as other formal actors propose ground level solutions favoring competing interests. Neither adequately considers future consequences for relevant publics left out of the process. People interested in resolving the ongoing spatial transport problems cannot grasp the effects on the urban grid of a cut-andcover2 tunnel solution or other surface train alignments. The formal efforts possess legal authority, but neither take practical steps to assess the spatial distribution of financial, environmental and social risks and benefits nor provide assurance of responsibility for these impacts.

\footnotetext{
1 The ERGOSE undertakes the management of OSE's Investment Program projects and in particular those cofunded by the EU Programs. The ERGOSE's tasks include planning, development, support, management, design, supervision, and construction of all types of projects for third parties in Greece and abroad, as well as land acquisition for the state or other public bodies.

2 The length of the ramps for a train to dig in a tunnel (with a proper inclination) is about $600-800 \mathrm{~m}$. This means that for a $1.5 \mathrm{~km}$ long tunnel across the historic city center, another $1.5 \mathrm{~km}$ of holes would divide residential areas. The estimated max. number of trains/day would be 2-3 per hour driving with a tram velocity through the residential areas.
} 


\section{Informal Planning}

Spatial planning includes a structure of authority and a culture of responsibility. Adoption of formal plans by local governing bodies would yield publicly beneficial results. But when faced with complex problems like in Patras, these currently work against one another. Spatial planning analysts urge a 'shift from government to governance' (Davoudi \& Strange 2009) hoping to redirect government authority to a diverse assortment of private non-governmental agencies that can more effectively respond to the interdependencies and uncertainty of complex changing situations (Bryson, Bromiley \& Jung 1990). However, government agencies and their private clientele possess their own culture that resists including non-governmental actors. Introducing cultural change requires that actors from both sectors learn together how to modify their respective beliefs, norms, styles and perspectives as they conceive problems and prospective solutions (Friedmann 2005; Getimis 2012). This requires purposeful imaginative intervention.

Informal typically refers to research, public outreach or other unofficial activities that prepare for formal planning or in some instances they may overlap (Scholl, Staub \& Vinzens 2013; Briassoulis 1997). But informal in this article refers to activities that share the authority and responsibility of formal planning more fully. Briassoulis (1997) uses three dimensions to analyze how informality and formality combine to govern places: authority (strong or weak), responsibility (inclusive or exclusive) and cost (high or low). She argues that informal planning emerges as governments regulate narrowly and people want publicly responsible actions; as governments regulate narrowly and planning costs are low; and in cases where governments exercise a lot of regulatory authority and planning costs are high. Informality supplements the formal system even as its activities involve many actors, agents and practices that remain poorly understood.

What does informality offer that the formal system does not? The informal system taps the insight of diverse social experience to improve practical judgments about complex problems. Planning in such settings embraces the conventions of deliberative democracy linking small group discourse with scientifically informed causal and interpretive analysis of problems and solutions. Based on the Habermas' (1984) theory of communicative action, the work by collaborative planning scholars provides an empirically tested assessment of communicative rationality: cooperation among numerous stakeholders, obtaining valid information, and exchange of information and different types of knowledge - expert and experiential (Forester 1989, 1999; Healey 1992, 1995; Innes 1995; Sandercock 1998; Booher \& Innes 2002). Innes and Booher (2010) further argue for the relevance of informal planning based on 
communicative rationality in the context of complex spatial problems. They elaborate five principles to use to judge if and when to collaborate. Table 1 summarizes each principle and what each tells us about the prospects for informal planning in Greece.

Table 1. Communicative rationality principles and their presence in the Greek planning system.

(Authors based on Innes \& Booher 2010: 209-211)

\begin{tabular}{ll}
\hline Communicative rationality principles & Practical effects \\
\hline Diversity and interdependence. Interdependence & Current practice tries to ignore or \\
among diverse actors motivates participation and & minimize interdependence and shed \\
spreads risk and reward as each contributes to joint & risk and concentrate benefits for a few. \\
conceptions of problem and solution. Learning about & Current practice frames development \\
mutual gains and risks encourages commitment to joint & issues as zero-sum contests pitting the \\
action now within an encompassing framework as future & proponents against others even as \\
commitments remain provisional - open to changing & complex relations undermine this view. \\
circumstances and shifting participants. &
\end{tabular}

Collaborative dialogue, trust and knowledge.

Collaborative dialogue among participants in small groups requires that each listen and learn from each other. Focusing on interests and intentions fosters trust as it informs judgments about causality and possibility. Future consequences replace attachment to rules and positions.

Networks. Networks among the stakeholders include a wide variety of possible interrelationships. This may include interdisciplinary cooperation, i.e. cooperation among various sectors within administrative structure, but also intersectoral cooperation, which includes mutual activities across public, private and civil sectors.

Monitoring and feedback. Accountability and responsibility animates the entire plan from the outset. Evaluation accompanies every phase because the plan provides an ongoing guide for relationships and not a blueprint.

Small, diverse working groups. Convening small temporary groups of people with a stake in a pressing complex spatial problem makes it possible to build relationships tied to resolving the problem. People are more willing to trust others and reconsider old habits in
Legal mandates and administrative procedures preclude the kind of conversation needed to avoid the pitfalls of adversarial positions and posturing. Ideological and personal commitments blind officials and clients to problem complexity and adaptive solutions.

Social networks supporting
administrative coordination and intersectoral cooperation are narrow and often tied to political clientele. Personal networks encourage exclusivity and privilege.

Formal plans often provide static blueprints for projects without details about accountability and feedback. Plans made without commitments avoid attention to impacts for others.

The layers of administrative authority promote asymmetrical communication, while crosscutting clientelism fosters exclusivity and suspicion. Groups form 


\section{The Test Planning Process in Patras: Theoretical and Practical Issues}

\section{The Method of Test Planning}

The test planning process (TPP) is the informal planning method for creating concrete and feasible proposals and solving the challenging tasks in spatial planning. It stimulates a critical discourse about implementing the solutions for complex and long-term spatial problems (Scholl, Staub \& Vinzens 2013; Scholl 2017). Instead of traditional/formal spatial planning methods, the TPP implies a collaborative process among numerous stakeholders with different interests that combines top-down with bottom-up approaches. More than a common competition, the TPP gathers competitive ideas from various planning teams coordinated by an interdisciplinary steering committee. The resulting contributions are presented, discussed and, after a close evaluation, passed on to an executive committee for further elaboration and implementation (Papamichail 2015; Scholl et al. 2015).3

According to Scholl, Staub \& Vinzens (2013), there are seven key principles immanent to test planning as a method:

- $\quad$ Concurrence of ideas. The core of test planning is the competition between various ideas. As a result, the most efficient solution is given to the contractor within the framework of the given conditions.

- $\quad$ Rhythm. Ideas and solutions mature due to repeated discussions and continuous testing throughout regularly scheduled meetings.

- $\quad$ No 'winner'. Unlike a traditional competition, there are no unique winning proposals. Since complex tasks often do not have ideal solutions, this method examines the different ideas of the teams and selects those that are most appropriate.

- Ad hoc organization. Test planning is an independent process and even the contributions of local and regional officials are considered according to the TPP rules. As a result, alternative, impartial solutions can emerge.

\footnotetext{
3 Many cities were pioneers in implementing the TPP, such as: Vienna's need for the Danube River flood protection (Vienna Model); Frankfurt's regeneration of the urban area along the Main River waterfront (Stadtraum Main), or Swiss cases of Solothurn's revitalization of one of the largest brownfields, and the transformation of the abandoned military airport Dübendorf (Scholl 2017).
} 
- Communication. Test planning cases are usually about areas whose future has a strong public interest. To gain public support for the results and attract various actors, communication and marketing of the various steps and solutions is important from the beginning.

- $\quad$ Finding problems and solutions. Apart from the final solutions, a redefinition or identification of new problems in addition to the given ones often takes place. This turns test planning into a dynamic process.

- $\quad$ 'Protected' process. Ideas and solutions are first discussed and tested in closed meetings between the teams and the steering committee before any public announcements in order to develop strong argumentation for the solution, which allows for a fruitful dialogue with various actors and the public to follow.

How well do the elements of the TPP incorporate the principles outlined in Table 1 ? Figure 1 offers a graphic image detailing important overlaps.

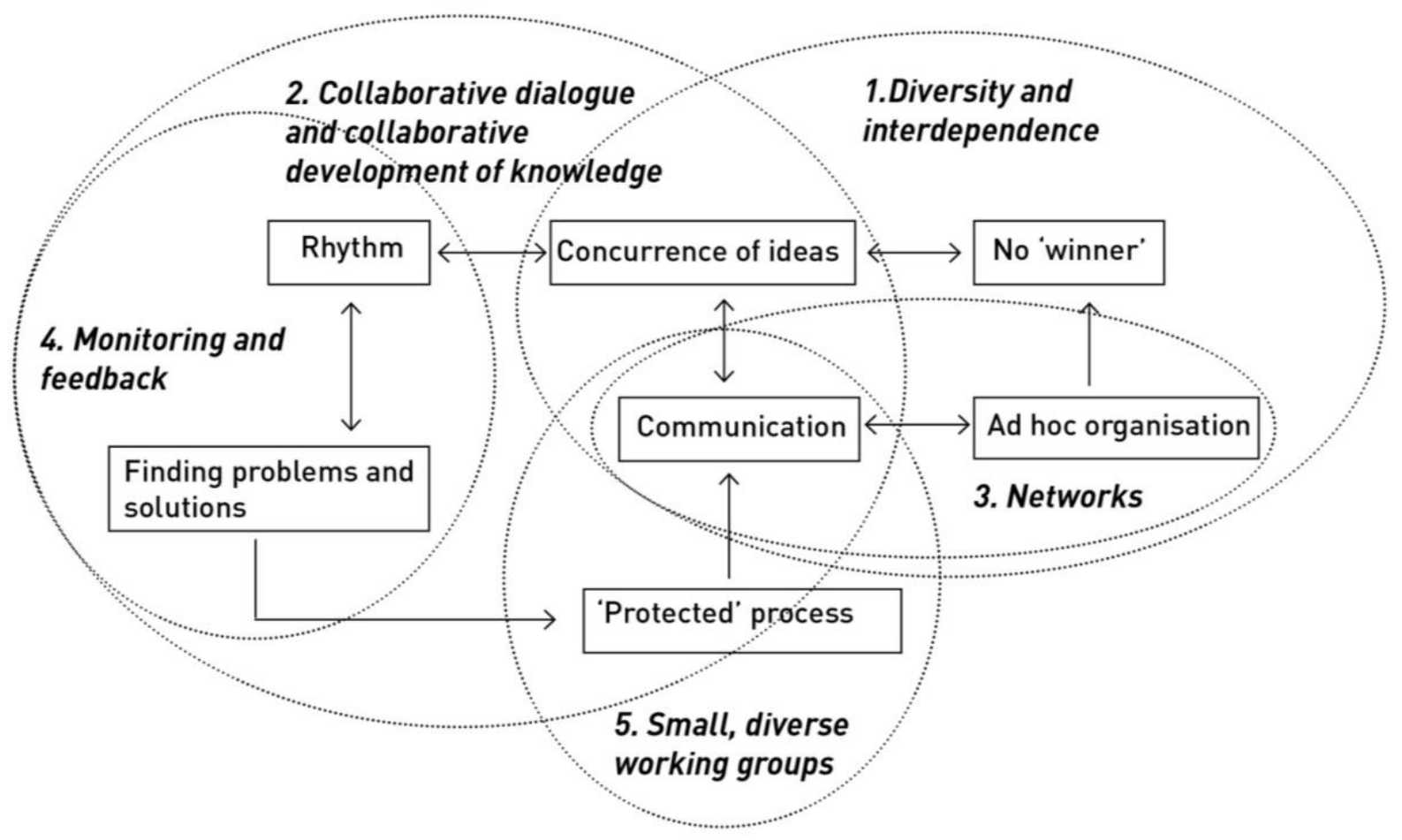

Figure 1. The interrelation between five principles of communicative rationality and seven principles of the test planning process.

(Source: Authors)

The next section describes the implementation of the TPP in Patras, revolving around the main communicative rationality principles and the extent to which they were applied. 


\section{The Implementation of the Test Planning in Patras}

The TPP in Patras was initiated due to the need of creating new railway station in the city's waterfront area. The dominant idea promoted by the railway companies was about creating the complex and expensive underground solution, while the ground-level option was not that much advertised. Therefore, the discussion about the alternative scenarios for sustainable development appeared to be necessary, and the implementation of an innovative planning method (TPP) was made possible due to the engagement of three universities (ETH Zurich, University of Patras - UP, and National Technical University of Athens - NTUA), whose representatives created the base for an open and transparent dialogue. The TPP comprises various stages - initiation, preliminary assessment, discussing the solutions, and monitoring and feedback, which last from six months up to one year. In the case of Patras, several steps preceded and followed the TPP itself, thus leading to a suitable environment for substantial knowledge-transfer and trust building among all the involved actors. These steps - pre-test planning phase, test planning process, and post-test planning phase (Figure 2), are briefly explained in the following sections.

Communication with the Public

Continuing communication: press release/publication, invitation and information of the stakeholders

Steps of the whole process in Patas

The pre-Test Planning Phase

The post-Test Planning Phase

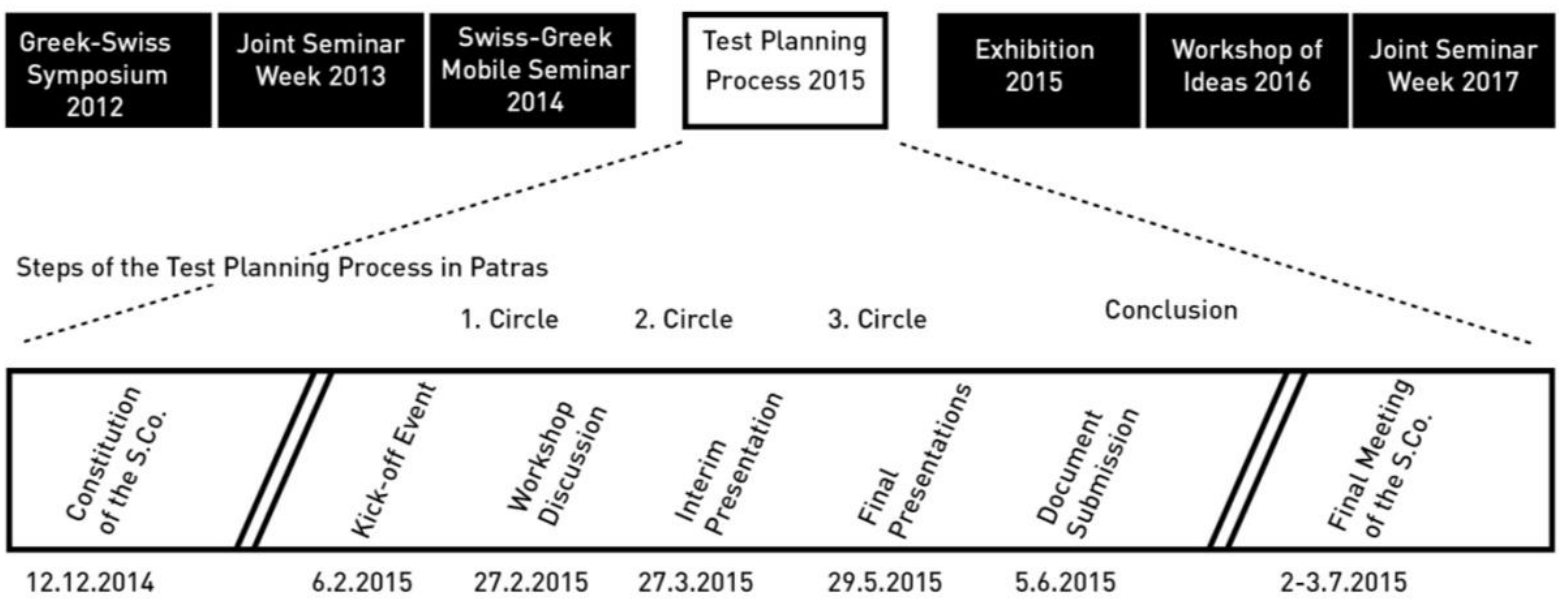

Figure 2. Timeline of the three-step test planning process in Patras.

(Source: Authors)

The Pre-Test Planning Phase: 2012-2014

The three main preliminary steps were undertaken before the official start of the TPP - the Greek-Swiss Symposium (preparatory meeting) in 2012, Joint Seminar Week (academic 
workshop) in 2013, and the Swiss-Greek Mobile Seminar in 2014. At the preparatory meeting (Figure 3), the representatives of the OSE, the ERGOSE, the former Patras municipality, academics and professionals from various domains met in Zurich to identify problems relevant to the railway and spatial development of Greece and the region of Patras. The Patras representative was open to further collaboration, while the ERGOSE fixated on a tunnel solution. During the Joint Seminar Week (Figure 4), small and diverse groups of Swiss and Greek students coordinated by interdisciplinary experts produced promising alternative ideas ready to be implemented in a stepwise manner. At the final presentation of the students' work, the Patras municipality, OSE, ERGOSE, and port authority representatives attended together with citizens. The ERGOSE representatives clearly insisted on the tunnel solution. The interests of the ERGOSE and the OSE converged at the beginning of the TPP; however, after the replacement of the its CEO, the ERGOSE started to be more open to perceive and discuss the ground-level solution for a new railway station. In February 2014, a Swiss-Greek Mobile Seminar was held in eastern Switzerland in order to explore the Swiss railway network in an area topographically similar to the Peloponnese region to which Patras belongs.

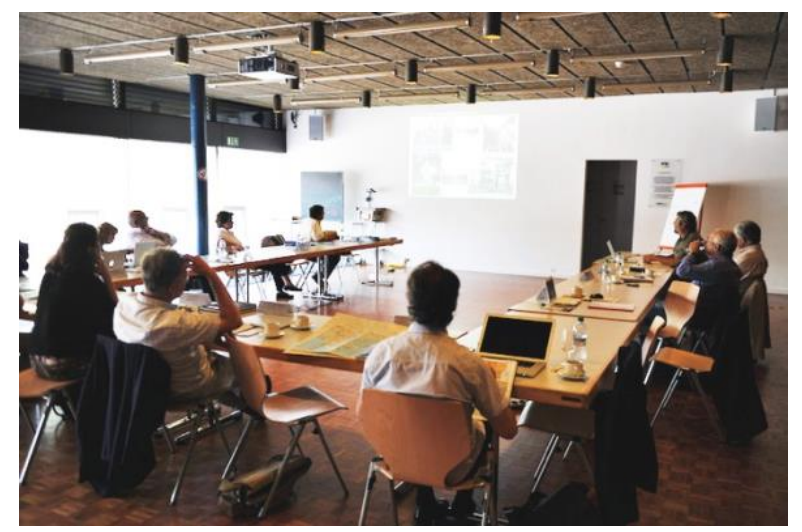

Figure 3. First preparatory meeting in Zurich in 2012.

(Source: T. Papamichail)

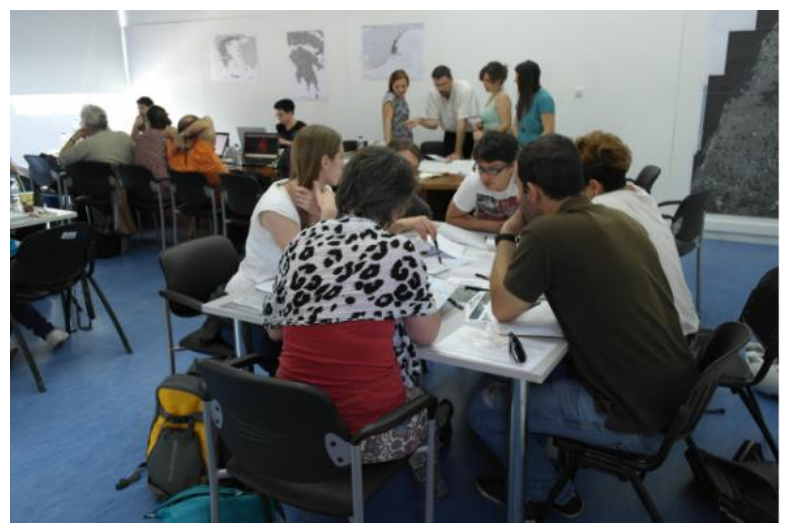

Figure 4. Students groups in intensive scenario discussion during the first Joint Seminar Week. (Source: V. Pappas)

The Test Planning Process: 2014-2015

The TPP itself lasted six months and included several key stages (Figure 2). In order to better understand the key steps of the TPP, it is necessary to briefly illustrate the main organizational structure of the stakeholders involved (Figure 5). As for the Steering Committee, it involved interdisciplinary expert team composed of spatial planners, transport engineers, landscape architects, etc. all belonging to various sectors, from academia to industry. In addition to their professional field knowledge, the previous expertise in similar planning procedures was a determining aspect for the experts to become part of the Steering Committee. 


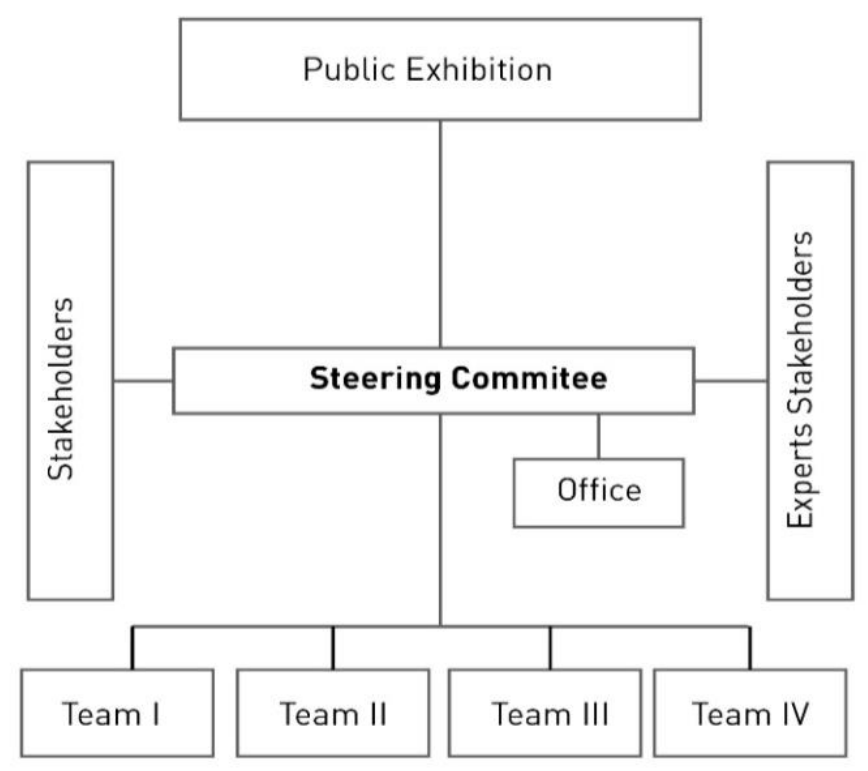

Figure 5. Organizational structure for the TPP in Patras.

(Source: Authors)

The creation and respect for common-shared knowledge guided the constitution of the Steering Committee. Relevant stakeholders - the OSE, the ERGOSE and municipal representatives were invited, even though only the OSE and the Port Authority (OLPA) had indicated support for informal planning. During the first cycle of the TPP, the Steering Committee and planning teams' discussion took place without stakeholders. This separation insulated the work of each planning team from bias for one or another stakeholder solution. Deliberations among the teams and the Steering Committee members in the first cycle considered three potential scenarios for transport integration: a by-pass, underground tunnel or ground-level solution. The pros and cons for each scenario were detailed and the teams prepared refined scenarios for a second and third cycle of deliberations. After each round the four proposals offered more compelling proposals that the members of the Steering Committee could use to compose a set of plan recommendations for public consideration.

The Steering Committee members interacted with the planning team members through mutual debate and discussion. The different viewpoints and arguments of each planning team was discussed extensively. An interesting insight of these debates was the location of the main railway station of the city. Three out of four teams considered the location of Agios Dionyssios (the area of the current railway station) as the most appropriate, while one team argued for the location close to the University campus. The Steering Committee did not reject such a solution, but both sides agreed that this station could serve as a complementary one in case of higher demand as a long-term measure. Another example concerns the inefficient plan of the by-pass solution, which was included in a separate documentation in order to proceed later with 
concrete arguments towards the stakeholders who insisted on this plan. Such an approach creates a repertoire of further solutions for any future debate.

The Post-Test Planning Phase: 2015-2017

The TPP plan recommendations were presented to the public to stimulate discussion and feedback about the possible solutions. Three events were staged to support this engagement: an exhibition (November 2015), an idea workshop (February 2016), and a one-week seminar (June 2017). At the exhibition (Figure 6) representatives of Patras municipality claimed the ground-level rail improvements recommended in the final Steering Committee proposal would introduce barrier walls through the community and along the coast blocking views and creating ugly physical separations. This adversarial critique ignored how the planning teams anticipated this risk and taken steps to integrate new rail lines without introducing massive physical disruptions. The OSE and ERGOSE representatives liked the ground-level options as did the ecologists focusing on environmental sustainability. The Municipality and the Technical Chamber of Achaia insisted on a tunnel, while the Port Authority (OLPA) remained neutral. During the workshop with citizens (Figure 7), many expressed their fears and new ideas.4 These included process concerns: "Why private and official transport agencies do not work (better) together?", in addition to some specific spatial proposals: "We expect the new railway station to create a new landmark in the city center". The Joint Seminar Week created working groups of Swiss and Greek students from three universities (ETH, UP and NTUA). They used the TPP plan information and the feedback from earlier events to inform their planning work. All came to support a ground-level solution but they made a compelling argument for Agios Dionyssios as the main railway station. $\mathrm{A}$ final joint meeting was scheduled for July 13,2017 , organized by the Ministry of Transport to provide feedback on final modifications and to adopt the recommendations for public action. Despite the organized meeting, the stakeholders have not yet agreed on a common final solution.

\footnotetext{
$4 \mathrm{~A}$ more detailed and complete overview of the recommendations can be found at www.codepatras.ethz.ch, as well as in the documentation of the Exhibition, 2015 and the Workshop of Ideas, 2016.
}

5 A publication on the results of the Joint Seminar Week 2017 will follow in autumn 2018. 


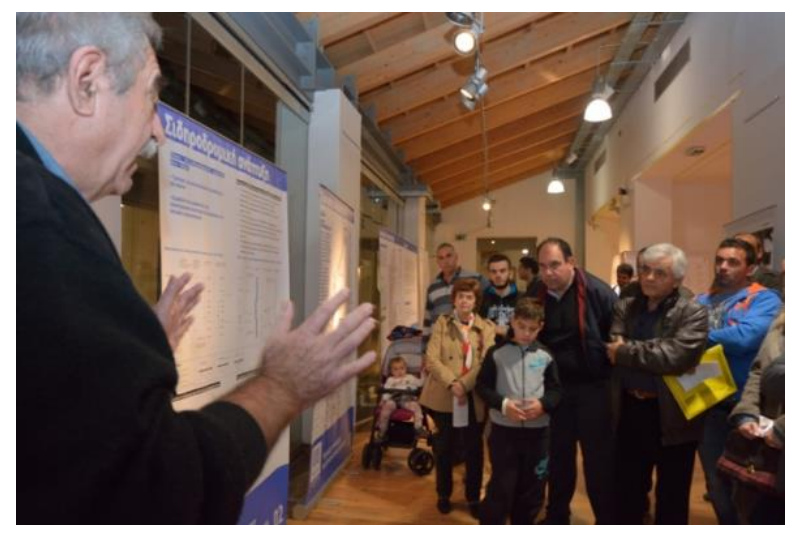

Figure 6. Guiding tours during the exhibition of the results of the TPP.

(Source: C. Bernhart)

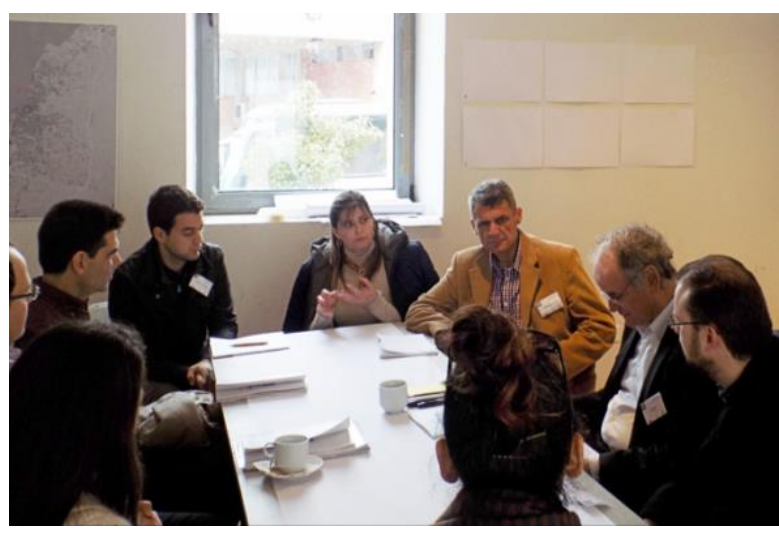

Figure 7. Roundtable with the citizens of Patras during the idea workshop. (Source: T. Papamichail)

\section{Discussion: The Impact of the Test Planning Process in Patras}

The TPP for Patras introduced informal planning for a variety of government stakeholders that remain tied to formal structure conventions and clientelist cultural norms. The Patras transportation problem posed an ongoing crisis despite repeated formal plan making efforts. However, some of the stakeholders agreed to try informal planning. Therefore, it is important to offer the systemic overview of the TPP characteristics based on its theoretical underpinning. More precisely, the next lines illustrate the analogy between the nature of the TPP and the communicative rationality principles as described by Innes and Booher (2010).

- The diversity and interdependence among the planning teams and the Steering Committee members assured diverse approaches to composing scenarios and tracking risks or benefits across multiple stakeholder interests. For instance, representatives from the railway company decided to opt for a less expensive groundlevel railway line than the tunnel. Municipal authorities learned how to obtain an economic profit from railway development that could fund the regeneration of the waterfront.

- $\quad$ Collaborative dialogue and knowledge. The TPP participation structure insulated participants from conventional roles as they engaged in dialog as members of the Steering Committee or planning team using discourse to compose and assess scenarios in terms of diverse interests. Integrating multi-disciplinary team work with political guidance diminished bureaucratic and clientelist influence. The unexpected 
emergence of a railway station at Agios Dionyssios, and continuing suburban rail service were not options on the planning horizon before this process began.

- $\quad$ New networks for collaboration. Suspicion and conflict precluded robust networking in this case. However, the TPP process provided a modest form of networking as it encouraged the OSE and the ERGOSE to join the process. Representatives from these organizations who held opposing positions at the beginning had found they could converge toward a common solution at the end. The cycles of plan making and the different collaborative events showed the institutional antagonists how reaching out and involving each other and citizens can change existing relationships and even lead to some new ones.

- $\quad$ Monitoring and feedback. The TPP builds assessment and feedback into the cycles of plan making linking expert and political judgment in the rhythm of working together. The TPP structure disrupts the influence of the formal planning process, but offers a complementary resource tapping democratic discourse for scientific and practical use in teams, committees and meetings that cut laterally across bureaucratic and political hierarchy. Each phase offers improved judgments about the meaning of the problem and the comparable merit of revised solutions. Goals do not target but guide.

- $\quad$ Small and diverse working groups. The TPP breaks formal bureaucratic plan making into a series of small group conversations focused on problem setting and solving efforts. The planning teams, steering committee and public engagement events each rely upon dialog among participants who care about the consequences for the situation at hand. For instance, the two Joint Seminar Weeks (groups of 6-7 students supervised by experienced professionals), the Exhibition (small sized guiding tours of 10-12 people followed by discussion), and the Workshop of Ideas (7-8 participants per roundtable) fostered small group dialog. These experiences not only improved the quality of plan ideas, but enhanced the legitimacy of the proposals while showing participants in the formal system how alternative informality can work.

Even though the TPP showed how informal planning might improve efforts to plan for a complex transportation problem, the approach has limitations. The following lines describe the shortcomings of the TPP influenced by local, i.e. Patras factors. The last paragraph gives, however, a broader picture on limitations of strategic spatial planning in Greece.

In Patras, planning experts were not involved in the discussion about the railway solution that greatly affects future urban development (Scholl et al. 2016). This is particularly true for the beginning phase of the planning process, while in its final stage the experts were involved as (mainly passive) observers. The reason for such a situation is their highly narrow and 
underestimated professional planning position - for planners it is pretty difficult to find a way to express interest for innovative planning procedures and to be part of it when the nature of the procedure overcomes the formal planning powers (Papamichail 2015).

Besides the lack of effective participation by local planners, the national administration (i.e. responsible ministries and national agencies) remains tied to centralized control and political clientelism. In February 2017, almost one year after the Workshop of Ideas as a follow-up event of the TPP, the Greek Ministry of Transportation hosted a discussion that included three scenarios of railway development for Patras - by-pass, the underground and the ground-level solution. They invited the port authorities, ecologists, political parties, the University of Patras and local organizations of neighbourhoods, but excluded the OSE, the ERGOSE, and other planning experts. After paying superficial lip service to the other options and completely ignoring the informal planning recommendation, the ministry proposed the $€ 700$ million bypass option. As the informal process pointed, such a solution is both infeasible and unpopular. Hence, there is little hopes of resolving the underlying spatial problem complexity as it undermines coordination among crucial actors and substitutes political patronage for publicly sensitive project effectiveness (Pappas, Kalamiotis \& Karidi 2013).

In July 2017, the public debate continued as all relevant actors (the OSE, the ERGOSE, the Patras municipality, the Ministry of Transportation, the port authorities, the ecologists, the University of Patras, etc.) met to provide feedback on the rollout of the ministry by-pass plan. Including and listening to all the actors (transportation companies, experts, academia) was a significant change for the ministry. TPP cannot bridge deep political divides, but offers a planning model for adopting informal planning in settings where complex spatial problems defy conventional solutions. As the by-pass project unravels and those familiar with the TPP process remember its value, the process may be revived, perhaps reframed as a home grown informal approach.

Finally, the success of the mentioned approach does not depend only on local factors, but also on the general planning conditions in Greece. These disable proactive role of planners at the local administrative level as bearers of strategic planning policy, and mediators in informed discussion among numerous stakeholders with various interests, as well. There are two main reasons behind such a situation. Firstly, local spatial planners are not formally competent to provide proposals that include even a pinpoint of strategic vision, i.e. strategic reasoning is reserved for the national planning offices within the relevant ministry, although it is highly ineffective. Local planners are in charge of providing building permits, thus supporting various decision-makers, mainly national government or private sector representatives (Othengrafen 
2010). Moreover, since each urban plan has to be in line with the national guidelines (and practically the plan is prepared by ministry), there is little room for local planners to show their possibly innovative approaches and a certain degree of independence. Briefly put, it is very hard to find a way for introducing integrated spatial and transport models (as truly strategic approach) within the highly centralised structure (Papamichail 2015). Finally, only in the last 15 years, it has been possible for students to obtain degrees in spatial planning (Othengrafen 2010). Most spatial planners were trained as architects who focus on designs for physical construction rather than make spatial plans offering alternative development strategies for future development. Additionally, the professional social and communication skills taught and used by spatial planners in the US and Northern Europe (negotiation, mediation, facilitation) are not used or taught in the Greek context (Papaioannou \& Nikolakopoulou 2016). Spatial planners involved in local planning do not know how to do the kind of informal planning that TPP puts to use.

\section{Conclusion}

The TPP for Patras shows how a model for informal planning helped people step outside their culture. They learned how informal professional collaboration can improve spatial plans. Therefore, the TPP proved useful in important ways even as the proposed recommendation did not obtain approval by national ministries (Scholl et al. 2015, 2016). Namely, the TPP contributed in the following:

- $\quad$ Pointed out a step-wise development including the strategic role of Patras in its future and an integrated approach to railway and spatial development, as proposed for the first time based on concrete arguments.

- $\quad$ Provided shared experience to inform later discussions, especially in the future application for the EU funding package (2020-2024) and so lead to proposals that improve the connectivity between Athens and Patras as the final railway section of the Orient/east-Med corridor.

- $\quad$ Showed how Patras might serve as a multi-modal and touristic hub for the regions of Western Greece and Peloponnese (an identity that few places can claim), and offering strategy and goals to make it happen.

- Showed how informal planning in southern countries might happen opening the door for further research. 
It is a chance for the city of Patras, as for other cities in crisis, to proceed with sustainable territorial management against privatization policies and a prolonged phase of underdevelopment. This can certainly be done through the substantial transformation of spatial planning, based on an interactive reciprocity between formal and informal planning procedures. As conceptually based on the notion of communicative rationality - revolving around mutual trust and understanding among numerous participants, in practice informal planning seeks to tap the problem-focused skills that people everywhere mobilize and use to cope with complex uncertainty. Since spatial planning has a long history of innovation relying on purposeful trial and error, the mental models or the so-called soft infrastructure within a certain institutional framework should be treated as fixed, but malleable (Healey 1997). Nevertheless, instrumental rationality, i.e. professional expertise, and the way how to improve planners' knowledge and skills in order for them to be able to cope with complex spatial problems involving conflicting stakeholders, is another condition to respect if striving to the change of the planning approach.

Such an integration between formal and informal planning, i.e. understanding informal as a supplement to formal planning procedures, is a key towards improved planning. However, it is not only that the modification of planning procedure, in terms of implementing some informal planning principles, will secure the long-term improved planning - i.e. the change of its nature. Informal planning is a tool, but a single procedure can lead to the transformation of a planning approach (e.g., from strictly formal to the formal-informal) only if there are broader contextual concerns fulfilled. Therefore, representative democracy is considered an obstacle for the creation and further implementation of proper measures needed for addressing the complex planning issues. Political patronage together with the Greek self-financed real estate development model make informal planning an exception rather than a norm when dealing with contemporary spatial problems. Spatial planning culture in Greece remains tied to a centralized bureaucratic conception of authority and an urbanist professional outlook (Knieling \& Othengrafen 2016; Papaioannou \& Nikolakopoulou 2016; Scholl et al. 2016). The situation is similar to the post-socialist states, where 'proto-democracy' limits the evolution of planning thought. The close feedback between national government and strong economic actors deeply affects the professional planners - they are incapable of promoting transparent planning procedures (Peric \& Miljus 2017). On the contrary, developed societies (with established system of social rules and norms for making the voices of all interested parties heard) provide a fertile playground for professional planning, too - planners are motivated for finding the innovative procedures and thus able to effectively swim in the whirlpool of various interests (Peric \& Hoch 2017). 
Reinforcing strategic decision-making and a step-wise development are the tools for paving the way towards a new planning culture. Nevertheless, changing planning culture is a longterm process, which may or may not be successful. However, it is not only on planners and their readiness to understand, accept new (communicative) skills and adapt these to the local settings. It depends more on the general socio-economic conditions which provide a secure and stable context for innovative planning to happen. For creating such circumstances, the systemic support is needed as a backbone - only in this case planning finds a fruitful ground for implementing informal procedures.

\section{References}

Booher, D., \& Innes, J. (2002). Network Power in Collaborative Planning. Journal of Planning Education and Research, 21, 221-236.

Briassoulis, H. (1997). How the Others Plan: Exploring the Shape and Forms of Informal Planning. Journal of Planning Education and Research, 17, 105-117.

Bryson, J.M., Bromiley, P. \& Jung, Y.S. (1990). Influences of context and process on project planning success. Journal of Planning Education and Research, 9(3), 183-202.

Buchner, H., Kohoutek, R. \& Pamer, V. (2004). Kabelwerk - A Development Process as a Model: The State of the Art. Vienna: City of Vienna.

Davoudi, S., \& Strange, I. (2009). Conceptions of Space and Place in Strategic Spatial Planning. Abingdon, Oxon, GBR: Routledge.

Foldi, Zs. (2006). Neighbourhood Dynamics in Inner-Budapest. A realist approach. Netherlands Geographical Studies no. 350. Utrecht: Utrecht University.

Forester, J. (1989). Planning in the Face of Power. Berkeley, CA: University of California Press.

Forester, J. (1999). The deliberative practitioner: encouraging participatory planning processes. Cambridge, MA: MIT Press.

Friedmann, J. (2005). Planning cultures in transition. In B. Sanyal (Ed.), Comparative Planning Cultures. New York: Routledge.

Getimis, P. (2012). Comparing Spatial Planning Systems and Planning Cultures in Europe. Planning Practice and Research, 27(1), 25-40.

Getimis, P., \& Giannakourou, G. (2014). The Evolution of Spatial Planning in Greece after the 1990s: Drivers, Directions and Agents of Change. In Reimer, M., Getimis, P., \& Blotevogel, H.H. (Eds.), Spatial Planning Systems and Practices in Europe (pp. 149-168). New York: Routledge.

Giannakourou, G. (2011). Europeanization, Actor constellations and Spatial Policy in Greece. disP The Planning Review, 47, 32-41.

Habermas, J. (1984). The Theory of Communicative Action - volume 1: Action, Reason and the Rationalization of Society. Boston: Beacon Press.

Hadjimichalis, C. (2011). Uneven Geographical Development and Socio-Spatial Justice and Solidarity: European Regions after the 2009 Financial Crisis. European Urban and Regional Studies, 18(3), 254-74. 
Healey, P. (1992). An institutional model of the development process. Journal of Property Research, 9, 33-44.

Healey, P. (1995). The institutional challenge for sustainable urban regeneration. Cities, 12, 221-230.

Healey, P. (1997). Collaborative Planning - Shaping places in fragmented societies. London: MacMillan Press.

Innes, J. (1995). Planning theory's emerging paradigm: communicative action and interactive practice. Journal of Planning Education and Research, 14, 183-189.

Innes, J. (1996). Planning Through Consensus Building: A New View of the Comprehensive Planning Ideal. Journal of American Planning Association, 62, 460-472.

Innes, J., \& Booher, D. (2010). Planning with Complexity: An introduction to collaborative rationality for public policy. New York: Routledge.

Keresztély, K. \& Scott, J.W. (2012). Urban Regeneration in the Post-Socialist Context: Budapest and the Search for a Social Dimension. European Planning Studies, 20(7), 1111-1134.

Knieling, J., \& Othengrafen, F. (2009). Planning Cultures in Europe: Decoding Cultural Phenomena in Urban and Regional Planning. Surrey: Ashgate.

Knieling, J., \& Othengrafen, F. (Eds.) (2016). Cities in Crisis: Socio-spatial impacts of the economic crisis in Southern European cities. New York: Routledge.

Komninos, A. (2014). Hellinikon: Tactics of Capital Urbanization and the Collective Superstructure. In Stuart, J., \& Wilson, M. (Eds.), Globalizing Architecture: Flows and Disruptions (pp.139-149). New York: Association of Collegiate Schools of Architecture.

Milionis, S. (2010). City Marketing in Greece: The Post-Olympic Use of Hellinikon Former Airport Site. Regional Science Inquiry Journal, 2, 151-172.

Newman, P., \& Thornley, A. (1996). Urban Planning in Europe: International Competition, National Systems \& Planning Projects. New York: Routledge.

Othengrafen, F. (2010). Spatial planning as expression of culturised planning practices: the examples of Helsinki, Finland and Athens, Greece. Town Planning Review, 81(1), 83-110.

Papaioannou, A., \& Nikolakopoulou, Ch. (2016). Greek cities in crisis: Context, evidence, response. In Knieling, J., \& Othengrafen, F. (Eds.), Cities in Crisis: Socio-spatial impacts of the economic crisis in Southern European cities (pp. 172-189). New York: Routledge.

Papamichail, T. (2015). Railway and urban development in Patras: Towards the improved participation of local governance in complex planning problems. Serbian Architectural Journal, 7(3), 365-380.

Pappas, V. (2017). Spatial planning in Greece, Lecture, MAS Program in Spatial Planning, European aspects of Spatial Planning, Symposium Part III, ETH Zurich, Zurich, February 7, 2017.

Pappas, V., Kalamiotis, I., \& Karidi, A. (Eds.) (2013). CODE PATRAS Joint Seminar Week, Urban and Railway Development in Patras: Report. Patras: University of Patras.

Peric, A. \& Hoch, C., (2017). Spatial planning across European planning systems and social models: A look through the lens of planning cultures of Switzerland, Greece and Serbia. In José Antunes Ferreira et al. (Eds.), E-Proceedings of the AESOP 2017 Conference "Spaces of Dialog for Places of Dignity: Fostering the European Dimension of Planning" (pp. 1247-1258). Lisbon: University of Lisbon. 
Peric, A. \& Miljus, M., (2017). Spatial and urban planning in Serbia: A look through the lens of deliberative approach. Spatium - International Planning Review, 37, 49-57.

Reimer, M., Getimis, P., \& Blotevogel, H.H., (Eds.) (2014). Spatial Planning Systems and Practices in Europe. New York: Routledge.

Romero, J., Jiménez, F., \& Viloria, M. (2012). (Un)sustainable territories: Causes of the speculative bubble in Spain (1996-2010) and its territorial environmental and sociopolitical consequences. Environment and Planning C: Government and Policy, 30, 467-486.

Roukouni, A., Basbas, S., Stephanis, B., \& Mintsis, G. (2016). The role of innovative transportation financing tools in achieving urban sustainability: a stakeholder's perspective. In Proceedings of the 11th International Conference on Urban Regeneration and Sustainability (pp. 585-596). Ashurst: WIT Press.

Sandercock, L. (1998). Towards Cosmopolis: planning for multicultural cities. Chichester: John Wiley and Sons, 1998.

Scholl, B. (2017). Building Actor Relationships and Alliances for Complex Problem Solving in Spatial Planning: The Test Planning Method. disP - The Planning Review, 53(1), 46-56.

Scholl, B., Frezadou, I., Milionis, N., Moraitis, K., Noser, P., Papamichail, T., Pappas, V., Signer, R., \& Vetsch, H-P. (2015). Code Patras - Rail \& City - A Test Planning Process for Patras. Zurich: ETH Zurich, Institute for Spatial and Landscape Development.

Scholl, B., Frezadou, I., Papamichail, T., \& Signer, R. (2016). Code Patras - Rail \& City, A Test Planning Process for Patras. Exhibition of the Results 2015/Workshop of Ideas 2016. Zurich: ETH Zurich, Institute for Spatial and Landscape Development.

Scholl, B., Staub, B., \& Vinzens, M. (Eds.) (2013). Test Planning - A Method with a Future. Zurich: vdf Verlag.

Vojvodiková, B. (Ed.) (2010). Brownfields - Handbook: Cross-disciplinary educational tool focused on the issue of brownfields regeneration - Educational tool for Latvia and Lithuania. Ostrava: Technical University.

Zifou, M. (2015). Greek Spatial Planning and the Crisis. In Eckardt, F., \& Sanchez, J. R. (Eds.), City of Crisis: The Multiple Contestation of Southern European Cities (pp. 155-178). Bielefeld: transcript Verlag.

\section{Declaration of interest}

Conflicts of interest: none 